\title{
Evaluating the pedagogical quality of international summer courses in a university program
}

Lakkala, Minna $\$

University of Helsinki, Finland (minna.lakkala@helsinki.fi)

Ilomäki, Liisa

University of Helsinki, Finland (liisa.ilomaki@helsinki.fi)

Mikkonen, Pauliina

University of Helsinki, Finland (pauliina.mikkonen@helsinki.fi)

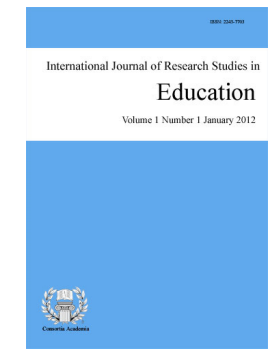

ISSN: 2243-7703 Online ISSN: 2243-7711

OPEN ACCESS

Muukkonen, Hanni

University of Oulu, Finland (hanni.muukkonen@oulu.fi)

Toom, Auli

University of Helsinki, Finland (auli.toom@helsinki.fi)

\section{Abstract}

The study evaluated the pedagogical quality of 16 university courses in a three-week international summer program. Short-term study-abroad programs have gained increasing popularity, but their pedagogical approaches have not been investigated widely before. Lesson observations, teacher interviews, and course materials were used to investigate the pedagogical approach of the courses. Answers to an online feedback form were used to examine students' study experiences. The courses were categorized into the following three pedagogical types: Self-directed academic studying, Practices of active learning, and Practices of shared expertise. Based on the survey data, the students valued the second and third types of courses more than the first type. Factors that students mentioned as positive in their open-ended responses were related to high-quality teaching arrangements, expert knowledge and practices, intercultural social interaction, and interesting and useful course content. Innovative pedagogy in international courses would include taking the multicultural assembly of participants into account to support multifaceted knowledge sharing and the development of cultural expertise in the target domain. The results can be used to create criteria and guidelines for subsequent courses, to develop feedback instruments, and in teacher training.

Keywords: short-term study abroad; pedagogical practices; university teaching; multicultural education; mixed-method research 


\section{Evaluating the pedagogical quality of international summer courses in a university program}

\section{Introduction}

Studying abroad provides university students with possibilities to develop both their academic expertise and intercultural competencies (Anderson, Lawton, Rexeisen, \& Hubbard, 2006). Especially short-term study abroad (STSA) programs have gained increasing popularity among students because they require less commitment and resources than longer programs and can, therefore, more easily be integrated with studying at their home universities (Donnelly-Smith, 2009; Torenbeek \& Meurs, 2012). Naturally long-term, e.g. a semester long, studying abroad usually have more significant and sustainable effect especially on students' identity development and intercultural competence (Dwyer, 2004). However, previous studies indicate that also participating in a STSA programme can be a worthwhile educational endeavour, for example, in terms of broadening understanding of one's own domain in an international context (Stanitski \& Fuellhart, 2003), training in intercultural sensitivity (Anderson et al., 2006), increased interest in interdisciplinary studies and perceptions regarding globalization (Lewis \& Niesenbaum, 2005), communication and language skills, or functional knowledge and multifaceted learning experiences (Chieffo \& Griffith, 2004).

In recent years there has been growth in international summer schools organized by universities. Torenbeek and Meurs (2012) define a summer school as one that "entails a relatively short course, taken during the summer break by students mainly from other institutions and other countries." (p. 2) Many European universities (e.g., Utrecht Summer School: http://www.utrechtsummerschool.nl/; University of Oslo: http://www.uio.no/english/studies/summerschool/; FUBiS: http://www.fubis.org/) have established international summer schools in which individual students may enrol. Summer schools have different focuses, e.g., in terms of internationalization and connections to official study programs and credits (Torenbeek \& Meyers, 2012). For an educational institution, international short programs may offer possibilities to experiment with new formats of teaching, gather experiences about international education, create new academic partnerships, expand curricula with international and interdisciplinary collaborators, and even contribute to a university's finances (Atkinson, Allert, Hirleman, \& Groll, 2006; Torenbeek \& Meyers, 2012).

International short programs that offer faculty-led academic courses for international students and aim at high-level academic learning outcomes are a relatively new phenomenon, and their best practices, benefits or effectiveness have not been investigated widely (Donnelly-Smith, 2008; Chieffo \& Griffith, 2014). Previous studies have focused on STSA programs that have been organized by the home department for its own degree students in the form of trips abroad in collaboration with universities in the visited countries (e.g., Lewis \& Niesenbaum, 2005), which are different kind of learning experiences than participation alone in an academic course in a foreign country.

STSA courses should provide participants with high-quality teaching based on academic and scientific foundations. Research into summer school programs and their pedagogy is still lacking, even though their number is rapidly increasing. The present study evaluated the pedagogical quality and students' experiences of the international courses of Helsinki Summer School, which is a three-week academic event organised every August by the University of Helsinki.

\subsection{Desirable pedagogy for international short term courses}

In summer schools, the students themselves choose the courses that are relevant for their studies; they are willing to pay for the participation, but they also require value for their money and time allocation. A critical factor for maintaining the good reputation of summer school programs and for recruiting new students in 
forthcoming years is that the courses should be of high quality. The scientific quality of the course contents and a possibility to earn grades for the students' degree programs are central factors for university-level STSA courses, but equally important is the overall experience of studying. Lizzio, Wilson, and Simons (2002) showed that student perceptions of the pedagogical methods are connected both with their satisfaction, approaches to study, and academic achievement.

Two key issues concerning the pedagogy of international short-term courses should be considered: first, what are the current conceptions of learning and innovative university pedagogy in general, and what are the issues that characterize and should be taken into account specifically regarding international courses?

When discussing the quality of higher education, the ideas of constructive alignment developed by Biggs (1996; Biggs \& Tang, 2011) are frequently quoted. In constructively aligned teaching, all teaching and learning activities, and assessment methods are planned in line with the explicated learning outcomes. This kind of pedagogy is based on the idea that learners integrate new knowledge to their existing knowledge structures and construct meanings when learning something. It is the teachers' task to structure aligned pedagogical activities and provide feedback to students in line with the learning goals. Related to constructive alignment, two vitally different approaches to teaching among university teachers have been distinguished (Postareff \& Lindblom-Ylänne, 2008; Prosser \& Trigwell, 1999): content-focused and learning-focused approaches. In the content-focused approach, teachers plan their teaching precisely, use rigid pedagogical practices, and emphasize remembering facts in their student assessments. Such teachers see themselves as content experts and do not pay much attention to the students' role, learning environment or atmosphere. Teachers representing the learning-focused approach emphasize a flexible planning process, contextual teaching practices, and understanding as the key focus of assessment. Such teachers define themselves as facilitators of learning and students as active agents in the learning process, and they emphasize interaction and the atmosphere as enhancing elements for learning.

Another relevant aspect in the discussion of the quality of higher education pedagogy is the integration of theoretical knowledge into real-life contexts; that is, the authenticity of the learning experiences and outcomes (Herrington \& Oliver, 2000). Authenticity in higher education settings means, for example, learning activities that have personal relevance for students in developing their academic or professional identities, simulate real-life settings of the domain, provide students with independence and responsibility, are based on complex, ill-structured and open-ended problems, treat students as competent knowledge constructors, or acquaint students with real contexts outside the university, e.g., through field trips (McCune, 2009; Stein, Isaacs, \& Andrews, 2004). Based on student interviews, Kember, Ho, and Hong (2008) suggested four key methods for increasing the relevance of higher education teaching: showing how theory can be applied in practice, establishing relevance to local cases, relating material to everyday applications, and finding applications in current newsworthy issues. In the study of Smyth et al. (2016), students reported that participation in authentic research activities during undergraduate studies increased their understanding of the nature of research and taught them skills that are relevant both in research and working life more generally.

The metaphors of learning introduced by Sfard (1998) and Hakkarainen, Palonen, Paavola, and Lehtinen (2004) provide alternative viewpoints to the discussion of university pedagogy. Sfard (1998) stated that, in addition to individual knowledge acquisition and focus on domain content, learning should be seen as contextual participation in social practices, through which also the norms, conventions and identities related to the domain or profession in question become relevant. Hakkarainen et al. (2004) complemented the idea by suggesting a third, knowledge creation metaphor that regards learning as a contribution in the processes of deliberate knowledge advancement and innovation in collaboration. Design principles for knowledge creation pedagogy highlight collaboration around developing shared objects, cross-fertilization of practices across communities of expertise (e.g., collaboration between people with different backgrounds), and application of digital technologies in knowledge practices (Paavola \& Hakkarainen, 2014). 
Concerning the pedagogy that is suitable especially for international settings, previous studies have mainly focused on issues related to advancing global awareness, multicultural competences or multiple social experiences (Deloach, Saliba, Smith, \& Tiemann, 2003; Donnelly-Smith, 2009), not on the quality of teaching or the promotion of academic expertise in general. Lauridsen and Cozart (2015) introduced quality principles for international classrooms, which included also such aspects as discussing about teaching approaches and expectations with students, clarifying teacher and student roles, and using students' diverse backgrounds as a resource in the course.

In the present study, we were interested in examining what kinds of pedagogical approaches the implementers of international short courses applied in promoting students' academic expertise; for example, how the possibilities for cross-fertilization between intercultural participants were exploited, or whether the teaching methods highlighted teacher-centered lecturing or student-centered, innovative ways of working, including social interaction, knowledge creation practices, authentic assignments and the use of digital tools.

\subsection{Aim of the study}

The aim of the present study was to investigate the pedagogical practices of courses organized in August 2014 in Helsinki Summer School. The organisers of HSS were interested in improving the pedagogical quality of the courses, and they aimed at concrete actions for improvements based on the results. Thus, the starting point for the study was practical. The review of previous studies did not reveal readily usable frameworks for examining the aspects that are relevant especially for evaluating the quality of teaching in STSA courses. We wanted to connect the study strongly with general educational theories and current research on developing university teaching. Therefore, a key aim was to create a categorization for examining the pedagogical practices in university courses, combining theory-based and data-driven viewpoints. For the study, three research questions were addressed:

$>\quad$ What kinds of pedagogical approaches and practices did the courses represent?

$>$ How did the students evaluate their course experiences?

$>\quad$ How were student evaluations related to the pedagogical type of courses?

\section{Methodology}

The general research approach followed a mixed-method strategy (Johnson \& Onwuegbuzie, 2004; Tashakkori \& Teddlie, 2003). Mixing methods allowed us to get information of both the pedagogical practices and student experiences in the STSA courses as well as the relationship between them. Using the terms suggested by Guest (2013) in describing the key methods of mixing, the timing of integration was sequential (the pedagogical categorization of courses was done first and then used together with students' course feedback). The purpose of integration was to compare two data sets and examine their relationship with each other (compare student feedback according to the pedagogical course type in order to investigate the relationship between the pedagogical approach and student satisfaction in the courses).

\subsection{Context and participants}

Helsinki Summer School is a three-week academic event organized by the largest and internationally highly ranked research-intensive university in Finland. It is especially targeted at international university students and graduates. The aim of the summer school is to invite students to learn about topical research issues in the Master's and Doctoral Programs of the University of Helsinki. The courses are strongly academic and multidisciplinary with multicultural groups of student participants. The HSS offering (15-20 courses each year) covers both undergraduate and postgraduate levels and a wide range of academic fields.

Each HSS course has a course coordinator who is responsible of organizing the course and is mainly in 
contact with the HSS office staff and students attending the course. In some courses, the coordinator also is the principal lecturer in charge of running the course and is frequently present in the classes. In other courses, a different person might act as the principal lecturer. In addition, several lecturers participate in running the courses or giving individual expert lectures. Most lecturers are from the hosting university, but several lecturers are also from abroad.

At the beginning of the study, the organizers of the HSS program sent an email to all year 2014 course coordinators informing about the study. Then the researchers contacted the coordinators or principal lecturers of each course asking about their willingness to participate. All 16 courses of HSS 2014 were included in the study. They covered the following research fields: Economics, Biosciences, Agriculture and Forestry, Humanities, Theology, and Social Sciences. Most of the courses were interdisciplinary. In total, 318 students participated in the investigated courses. They represented 50 different nationalities; $25 \%$ of the students were doing their degree in Finland ${ }^{1}$.

\subsection{Data collection}

The following data were collected to examine the pedagogical practices of the courses:

$>\quad$ Course materials from the HSS public website (e.g., brochure and programme) and from the HSS extranet (an electronic platform for distributing materials to the students). In some courses, the extranet included only the course description and schedule, in other courses it was used more extensively to distribute presentation materials, articles and guidelines.

$>$ Observation notes from one observed session (about two hours) of each course. The time of observation was agreed on with the course coordinator or principal lecturer. If possible, course sessions that included not only lecturing, but also active student participation, group work, or interdisciplinary collaboration were chosen for observation. Two researchers conducted the observations; each session was observed by one researcher. A description of activities during the session was recorded in chronological order as written notes. Especially the following aspects were observed and documented: what did the students do during the session (the nature of activities and tasks); the relationship between collaborative and individual work; cross-fertilization practices, also from the multicultural perspective; the use of digital technology; authenticity of course content and practices (e.g., theoretical, procedural or applied knowledge, or expert models and concrete examples); and the role of lecturers during the session.

$>$ A short semi-structured interview of the observed lecturer or course coordinator, usually arranged after the observation. The interviews were conducted in Finnish or English, depending on the preference of the interviewee. The interview questions were the following: "What are the main goals of the course? What kinds of pedagogical ideas were used during the course? What kinds of concrete ways of working and tasks are used in the course?" In addition, the course programme was available during the interview, and it was used to elicit additional questions about the course.

One lecturer or course coordinator from each course was interviewed. The classroom observation was conducted on 15 out of the 16 courses. One course observation could not be arranged because of timetable clashes. To compensate for this, we made a more comprehensive interview with the coordinator, discussing the course design in more detail.

The following data were collected about the students' experiences:

\footnotetext{
1 Additional note: Although that $25 \%$ of the participants in the courses were degree students from Finnish universities, but many of them were foreigners, not Finnish in their nationality.
} 
$>$ Students' answers to statements in an online feedback form. The statements used the Likert-scale; from 1 = Unsatisfactory to $5=$ Excellent. Students were asked to evaluate the following aspects of the course: (1) Correspondence of the course content with the title; (2) Correspondence of the academic content with the students' expectations; (3) Structure and organization of the course and its contents; (4) Overall level of teaching; (5) Quality of English spoken by teachers; (6) Course literature and other material; (7) Course assignments, and (8) Facilities provided by the universities.

$>$ Students' responses to two open-ended questions: What has been positive or impressive in the course? What has been negative or challenging in the course?

The feedback statements were from the form that the summer school organizers had used already for several years to collect feedback from students. The statements were not originally developed for research purposes, but the organizers wanted to be able to compare the results to the feedback from previous years. The two open-ended questions were adopted from previous studies investigating students' self-reported experiences in university courses (e.g., Lakkala, Toom, Ilomäki, \& Muukkonen, 2015).

Approval for this study was obtained from the Academic Steering Committee of the Helsinki Summer School. In addition, an informed consent was collected from the observed and interviewed lecturers. Students answered the feedback form anonymously.

\subsection{Data analysis}

The classification of the courses based on their pedagogical approach was created through abductive use of theory-informed and data-grounded analysis on the data (Timmermans \& Tavory, 2012). The unit of analysis was the whole course, and apart from the student feedback the analysis covered all the data from each course including: materials, session observations, and teacher interviews. Two researchers examined the data several times, and the classification was constructed and applied to the data through discussions between the researchers. First, an overview of the structure and pedagogical design of each course was derived from the course schedules (e.g., the proportion, variety, and timing of lectures and other activities). Second, session observations were used to provide information about concrete learning activities, students' collaboration with each other, the social atmosphere, and the working culture in general. Third, teacher interviews gave more detailed information about the overall goals and pedagogical approaches of the course as well as the variety of working methods used. Other course materials, such as brochures, guidelines and teaching materials were used as complementary data. The theoretical viewpoints of constructive alignment, content-focused and learning-focused approaches to teaching, authenticity and the three metaphors of learning were used as theoretical starting points for examining the courses. The final categorization was created in a data-informed way.

Each course was categorized into a pedagogical course type based on the combination of features in the course practices and the predominant pedagogical approach that they represented. The following three categories were created to represent the pedagogical types:

$>\quad$ Self-directed academic studying: The courses in this category included rather a small number of contact sessions, mainly consisting of lectures and whole-class discussions, and independent individual and group tasks outside the contact lessons. Studying content was emphasised.

$>$ Practices of active learning: These courses typically included a rich variety of student-centred activating tasks, such as discussions, group presentations, readings, learning diary assignments, or excursions, in addition to expert lectures. Good comprehension and mastery of key academic domain knowledge was highlighted.

$>\quad$ Practices of shared expertise: In this type of courses, students were engaged in applied tasks that included authentic knowledge and methods from the professional or scientific world of work; such as 
collaborative problem solving, project- and case-based learning, field work, and sharing of multicultural and multidisciplinary knowledge. The focus was on acquainting students with topical research endeavours and expert-like practices of the domain.

Students' answers to the statements of the feedback form were analysed using the IBM SPSS Statistics v.22 program. The courses were categorized based on their pedagogical type as described above, and for each type, the means of the evaluation statements were counted. After that, the means of the statements of each pedagogical course type were compared using one-way ANOVA and Scheffe's post-hoc tests.

Students' open-ended responses about positive and impressive or negative and challenging aspects of the course were categorized by applying data-driven thematic content analysis (Braun \& Clarke, 2006). In all, 355 excerpts involving praising viewpoints, and 230 excerpts involving critical viewpoints were derived from the answers. The following main categories were constructed to categorize the excerpts based on a data-driven analysis:

Positive or impressive aspects

$>$ Satisfactory teaching arrangements: Mentions in this category concerned general praising of the lecturers, quality of teaching, course design and organization as well as methods, materials, facilities and the atmosphere of the course.

$>$ Expert knowledge and practices: Evaluations in this category addressed excursions and field trips, a multidisciplinary approach to content, the contribution of expert lecturers as well as authentic assignments, practical content, research-based content, and academic contacts.

$>$ Intercultural social interaction: Issues in this category were related to the impact and benefits of social interaction, group work, and the multicultural and multidisciplinary composition of the participants.

$>$ Interesting and useful content: This category was applied to general positive mentions about the course content or its coverage and scope, and about the respondent's own content learning.

Negative or challenging aspects

> Uninspiring knowledge and activities: This category included mentions about narrow content focus or expertise of lecturers; low academic level; too much lecturing instead of practical work, and low course requirement levels.

D Heavy workload and time constraints: This category was applied to comments about not having enough time to complete the tasks; too many tasks and too much to do, and not enough time to participate in free-time activities.

D Unsatisfactory teaching arrangements: Mentions in this category included criticisms about unclear assignments, poor lectures, poor course organization, not enough guidance, or poor accessibility to materials.

$>$ Challenges with content learning: Mentions in this category were related to difficult content of the course or reading materials; shortcomings in the respondents' own background knowledge, and difficult individual assignments.

$>$ Challenges with intercultural social interaction: Mentions concerned poor English language skills of the respondent or other participants and lecturers, or difficulties related to group work.

After the categorization of the students' free-text answers, the pedagogical course types and the students' course evaluations were combined by examining the distribution of evaluations into positive/impressive and negative/challenging issues separately for each pedagogical course type. The Chi square test was used to 
Lakkala, M., Ilomäki, L., Mikkonen, P., Muukkonen, H., \& Toom, A.

examine the difference between the pedagogical course types.

\section{Results}

\subsection{Pedagogical approaches and practices in the courses}

All the investigated courses offered profound academic perspectives on the topic under study. In some courses, one lecturer was responsible for most lectures, other courses were organized as a series of lectures where each lecturer had only one or two lessons. For almost all the courses, academic pre-readings, or readings during the course were offered or even required; such assignments emphasized the aim for a high academic level. All the courses included other activities besides lectures, but in some courses their role was minor.

Based on the observations, some lecturers were excellent in creating interaction with students during lecturing. They provoked, asked questions, and used comparisons, metaphors and other rhetoric means. Other lecturers used short tasks which activated students to discuss or collaborate with their peers; for example, texts to be discussed, or practice-related problems to be solved. There were, however, also lectures which had no interaction, or only a few participants were involved in teacher-led discussions.

The use of digital technology was not very extensive in the courses although the organising university offered digital tools. Digital learning platforms were used in only a few courses, some courses used the extranet to distribute materials. In some courses the research articles to be read were even distributed in paper form.

Based on the analysis, the courses were divided into the three pedagogical course types as follows: Self-directed academic studying, four courses; Practices of active learning, five courses, and Practices of shared expertise, seven courses. Below is a summary of the courses and the characteristics for each type.

Self-directed academic studying - The four courses in this category included rather small numbers of contact sessions, and the structure and practices were quite homogenous throughout the course. The courses had only about two contact hours daily, consisting of either expert lectures or student presentations, all other work was independent individual reading and writing tasks, or group work outside the classroom. One course had also two short field trips. The lecturer of a course described her teaching in the following way:

... I have myself quite conservatively only lectured in a traditional way. Mainly I have tried to think how to make the structure of my lectures as clear as possible so that the students could easily follow them.

We may say that the instructors in these courses acted as conventional academic lecturers, who emphasized self-directed studying and the acquisition of domain content. One teacher described the pedagogical rationale as follows:

Such that students should take responsibility themselves. Especially through the discussions and assignments we try to make students think, ponder and reflect for themselves. It is true we give quite a lot of tasks and reading assignments and there is quite a lot of traditional lecturing. Yes, the emphasis is on making the students start thinking and processing by themselves.

Practices of active learning - All five courses in this category had many activities with all-day schedules. The methods included a rich variety of student-centred activating tasks, such as discussions, workshops, group work, student presentations, readings, learning diary, excursions, and field trips in a well-balanced way. However, the emphasis still was on expert lectures and content learning. Comprehension, mastery and application of key academic knowledge of the domain was highlighted by the lecturers; for example:

To give a basis for applying this knowledge that is available in the course later in their own countries and their own studies. To function short of extra-curricular education. 
In addition to academic instructors, the lecturers worked as guides who focused on supporting students' learning in content mastery, which is nicely illustrated in the following quotation:

I think it's very much the idea of this course, we see ourselves as guides. So, we know the field very well and then we choose certain big sites. We walk together with the students; we guide them through this landscape of national studies. But then we choose certain elements that we consider to be most relevant and most interesting.

Practices of shared expertise - The seven courses in this category included lectures given by a variety of experts, either university researchers or professional experts outside universities. Most courses had multiple excursions or field trips to relevant field sites, research units, companies or organizations. Students' assignments resembled authentic research or working practices rather than learning tasks, such as workshops, poster presentations, seminars, case studies, or experimental projects. The promotion of students' roles as experts was described by one teacher in the following way:

Students complete assignments in groups. There are certain theme areas, they discuss these themes and make poster presentations about them. Then they all present their posters to the whole class and we discuss the presentations. There is some role playing also; they are, for example, teams of young scientists, and they have to, as a group, tell others who have to listen as an audience. The teams are asked questions based on the idea that they are the experts of certain design situations.

In many of the observed sessions in this course category, the participants' international and multidisciplinary backgrounds were taken into use to enrich the viewpoints. Multiculturalism was also emphasized in some of the lecturer interviews; for example:

Well, lecturers have been instructed to take into account the huge variety of differences ... that students come from so many different backgrounds, and this needs to be used as a resource, or it's beneficial to use these differences, and it also has happened.

Lecturers more or less took the role of expert participants, presenting their own topical and significant research endeavours, acquainting students with authentic working practices, and supporting them in developing professional and academic expertise. A teacher described the pedagogical approach as follows:

Four hours of lectures a day, quite quickly kills the students' enthusiasm. We make them work instead, make them solve issues under our guidance. And then we have much practical laboratory work, where they are able to use devices that are worth millions; they can really use the tools that expert researchers use.

\subsection{Students' evaluations of the course experience}

In all, 278 students (on average 17.4 students per course) answered the online feedback form, which was $87 \%$ of all participants of the HSS 2014 courses. Table 1 presents the means and standard deviation of the students' answers to the eight course feedback statements separately for each pedagogical course type. Results in Scheffe's post-hoc tests, the mean scores of courses representing self-directed academic studying were significantly different from the two other types of courses. Only the evaluation of university facilities was constant across the course types. There was no statistically significant difference in mean scores between the courses representing practices of active learning and practices of shared expertise. While, Table 2 presents how the positive or impressive and negative or challenging factors mentioned by students in their free-text answers were distributed in the different analysis categories in the data from all the courses. 
Lakkala, M., Ilomäki, L., Mikkonen, P., Muukkonen, H., \& Toom, A.

\section{Table 1}

The means and SD of evaluation statements in different types of courses, and the differences per statement

\begin{tabular}{|c|c|c|c|c|c|c|c|c|}
\hline \multirow{2}{*}{$\begin{array}{l}\text { Course type } \\
\text { Statement } \\
\end{array}$} & \multicolumn{2}{|c|}{$\begin{array}{c}\text { Self-directed } \\
\text { academic } \\
\text { studying } \\
\end{array}$} & \multicolumn{2}{|c|}{$\begin{array}{c}\text { Practices of } \\
\text { active learning }\end{array}$} & \multicolumn{2}{|c|}{$\begin{array}{c}\text { Practices of } \\
\text { shared expertise }\end{array}$} & \multirow[b]{2}{*}{$F(2,275)$} & \multirow[b]{2}{*}{$p$} \\
\hline & Mean & $S D$ & Mean & $S D$ & Mean & $S D$ & & \\
\hline $\begin{array}{l}\text { 1. Correspondence of the } \\
\text { content of the course } \\
\text { with its title }\end{array}$ & 3.6 & 1.118 & 4.4 & 0.860 & 4.4 & 0.773 & 20.870 & .000 \\
\hline $\begin{array}{l}\text { 2. Correspondence of the } \\
\text { academic content with } \\
\text { my expectations }\end{array}$ & 3.5 & 1.243 & 4.3 & 0.866 & 4.1 & 1.005 & 12.891 & .000 \\
\hline $\begin{array}{l}\text { 3. Structure and } \\
\text { organization of the } \\
\text { course and its content }\end{array}$ & 3.4 & 1.177 & 4.3 & 0.863 & 4.2 & 0.841 & 23.783 & .000 \\
\hline $\begin{array}{l}\text { 4. Overall level of } \\
\text { teaching }\end{array}$ & 3.7 & 1.113 & 4.4 & 0.655 & 4.4 & 0.729 & 18.286 & .000 \\
\hline $\begin{array}{l}\text { 5. Quality of English } \\
\text { spoken by teachers }\end{array}$ & 4.1 & 0.967 & 4.4 & 0.769 & 4.6 & 0.686 & 9.850 & .000 \\
\hline $\begin{array}{l}\text { 6. Course literature and } \\
\text { other materials }\end{array}$ & 3.8 & 1.230 & 4.3 & 0.719 & 4.4 & 0.668 & 9.850 & .000 \\
\hline 7. Course assignments & 3.6 & 1.101 & 4.1 & 0.930 & 4.1 & 0.896 & 8.958 & .000 \\
\hline $\begin{array}{l}\text { 8. Facilities provided by } \\
\text { the universities }\end{array}$ & 4.4 & 0.739 & 4.5 & 0.770 & 4.6 & 0.645 & 8.958 & .306 \\
\hline
\end{tabular}

Table 2

Distribution of factors in students' mentions of positive or impressive and negative or challenging factors

\begin{tabular}{|c|c|c|c|c|c|}
\hline \multicolumn{3}{|c|}{$\underline{\text { Positive or impressive factors }}$} & \multicolumn{3}{|c|}{$\underline{\text { Negative or challenging factors }}$} \\
\hline Category & $F$ & $\%$ & Category & $F$ & $\%$ \\
\hline $\begin{array}{l}\text { Satisfactory teaching } \\
\text { arrangements }\end{array}$ & 126 & 35.5 & $\begin{array}{l}\text { Uninspiring content and } \\
\text { activities }\end{array}$ & 61 & 26.5 \\
\hline $\begin{array}{l}\text { Expert knowledge and } \\
\text { practices }\end{array}$ & 107 & 30.1 & $\begin{array}{l}\text { Heavy workload and time } \\
\text { constraints }\end{array}$ & 50 & 21.7 \\
\hline $\begin{array}{l}\text { Intercultural social } \\
\text { interaction }\end{array}$ & 79 & 22.3 & $\begin{array}{l}\text { Unsatisfactory teaching } \\
\text { arrangements }\end{array}$ & 47 & 20.4 \\
\hline \multirow[t]{2}{*}{$\begin{array}{l}\text { Interesting and useful } \\
\text { content }\end{array}$} & 43 & 12.1 & $\begin{array}{l}\text { Challenges with content } \\
\text { learning }\end{array}$ & 36 & 15.7 \\
\hline & & & $\begin{array}{l}\text { Challenges with intercultural } \\
\text { social interaction }\end{array}$ & 36 & 15.7 \\
\hline Total & 355 & 100.0 & & 230 & 100.0 \\
\hline
\end{tabular}

As Table 2 shows, general teaching quality issues and expert-level knowledge and practices on the one hand, and criticism of uninspiring or low-quality teaching on the other hand, received more attention from the students than mere intercultural aspects. High-quality teaching arrangements were praised, for example, in the following way: "Positive was that some lecturers were really good and provided interesting lectures." or "It was overwhelming how much effort was put in it to make us feel as comfortable as possible and prepare us for the work and lectures". Expert knowledge and practices were described, e.g., as follows: "It has been positive to see real life examples from researchers who are actually studying local issues" or "Also, I enjoyed the field work and learned a lot in that environment."

The students' free-text evaluations were also examined separately for the different pedagogical course types. In the four courses representing self-directed academic studying, there were almost the same amount of comments about positive/impressive $(F=96)$, and negative/challenging $(F=92)$ factors. In the courses including practices of active learning, the number of positive/impressive factors $(F=97)$ mentioned by students 
was clearly higher than negative/challenging factors $(F=59)$. In the courses representing practices of shared expertise, positive/impressive factors were mentioned twice as much $(F=162)$ as negative/challenging factors $(F=79)$. The differences in the profiles of frequency distributions are presented in Figures 1 and 2.

Figure 1. Results of the thematic analysis of students' answers to the open question 'What was positive or impressive in the course?' according to the pedagogical course type

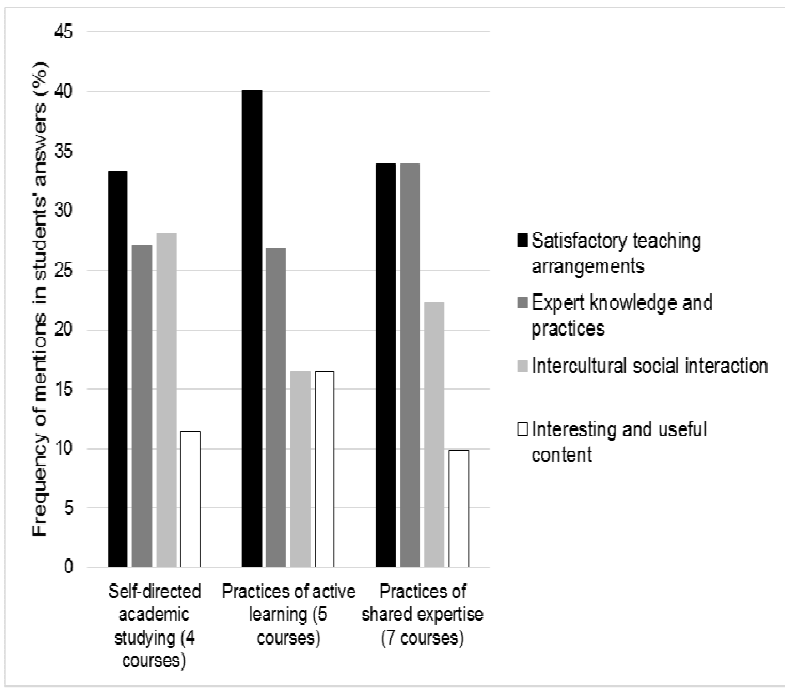

As Figure 1 shows, the distribution of factors addressing positive or impressive issues is quite similar in all the pedagogical course types. According to the $\chi 2$-test, there was no statistically significant difference in the distribution of frequencies between the three course types, $\chi^{2}(6, N=355)=7.451, p<0.281$.

Figure 2. Results of the thematic analysis of students' answers to the open question 'What was negative or challenging in the course?' according to the pedagogical course type

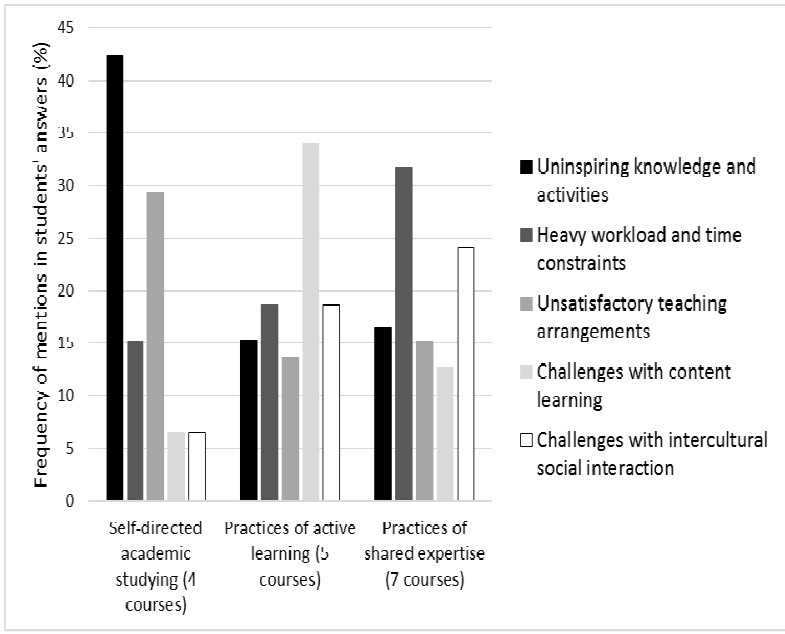

As can be seen from Figure 2, the profiles of the three pedagogical course types deviate clearly from each other when comparing the issues that students' mentioned concerning negative factors. According to the $\chi 2$-test, the differences in the distribution of frequencies between the course types is statistically significant, $\chi^{2}(8, N=$ $230)=52.9009, p<0.000$. In the courses that represented self-directed academic studying, the most often mentioned unsatisfactory aspects were uninspiring knowledge and activities (e.g. "The lessons were completely frontal and traditional without interaction", or "The topics of this assignments were not really interesting (for me)"); as well as unsatisfactory teaching arrangements; e.g. ("The lack of continuous (or any) feedback during the course; too much reliance on students sharing their experiences, not enough structured teaching/discussion"). In the courses representing practices of active learning, in which the pedagogical goals and methods focused on the understanding of academic knowledge, students mentioned challenges with content learning most often, for example: "Also the readings we were supposed to read (I found some of them quite difficult)". A heavy workload and time constraints as well as challenges with intercultural social interaction were experienced as negative and challenging factors especially in the courses where the activities resembled practices of shared expertise - many 
tasks in these types of courses were quite demanding knowledge creation and problem-solving assignments carried out in teams. The following are quotations from these courses: "Challenging were the very packed schedules and little time to work on the group assignments" and "Maybe the English language (dis)ability of some students limited the quality of discussion-based learning we could have had".

\section{Discussion}

It was promising that most of the 16 courses investigated represented pedagogical approaches rich in methods and emphasizing students' active involvement. Particularly in courses representing practices of active learning and practices of shared expertise, teachers apparently succeeded in designing pedagogy that followed the logic of student learning, not the logic of the teacher's expertise, or the structure of the content. However, we evaluated one fourth of the courses to represent very conventional teaching styles.

The three pedagogical course types, constructed through the interplay between theoretical perspectives and empirical data, revealed interesting, fundamental differences in the teaching approaches of the courses. In the first course type, Self-directed academic studying, the pedagogical emphasis resembled the content-focused approach to learning (cf. Prosser \& Trigwell, 1999), whereas the working methods and teaching arrangements in the second course type, Practices of active learning, followed the principles of constructive alignment (Biggs \& Tang, 2011). Evaluated through the three metaphors of learning (Hakkarainen et al., 2004; Sfard, 1998), both course types mainly represented the acquisition metaphor of learning: the emphasis was on individual learning of domain knowledge, and collaborative and student-centred activities were deployed to serve the advancement of individual knowledge acquisition. The courses in the category Practices of shared expertise, instead, applied methods that are expected to develop broader academic or professional expertise including, in addition to content mastery, also practical skills, working strategies, collaboration and networking, knowledge of topical trends in the field, creation of new solutions, and identity as an expert, among others (Hakkarainen et al., 2004; Mieg, 2001). The three pedagogical course type categories, identified in the study, offer a useful framework for evaluating the pedagogical characteristics, quality and innovativeness of higher education courses also more generally.

Courses representing traditional teacher-centred lecturing combined with independent work (Self-directed academic studying) received, on average, the weakest scores from students in the evaluation statements. Courses of that type have a strong and long tradition in university education, but we believe that they are not the most suitable for voluntary international short courses especially from the viewpoint of providing students with novel, impressive study experiences in an international context. The two other course types, Practices of active learning and Practices of shared expertise, offered more student-centred and collaborative activities, without losing the high-level academic stance. In the open-ended responses, the number of positive factors mentioned by the students were much higher than negative factors especially in the third type of courses which can be regarded as pedagogically most innovative, representing practices of shared expertise. However, both positive and negative factors were mentioned concerning all the courses. For example, many participants mentioned traditional teacher-centred lecturing in negative terms, but some students from the same courses were satisfied with the teaching arrangements. Students may have differing studying experiences in their home universities, and are, therefore, accustomed to different types of teaching methods.

Multicultural aspects and social interaction were issues frequently mentioned by students in their feedback both concerning impressive and challenging aspects of the courses. However, those issues were not the most central when students wrote about their satisfaction with the course experience. This result is in line with the notion presented by Torenbeek and Meurs (2012) that students are not participating in STSA courses only for getting international experience; they also seek academic value and high-quality study possibilities. 


\section{Conclusions}

The results of the study indicate that although student-centred and expert-like practices are challenging students, e.g., are responsible for the group outcomes and have to collaborate with participants from different cultural backgrounds - students also appreciate this type of pedagogy. The participants, particularly, appreciated student-centred and collaborative activities in courses that were also of a high quality in terms of their scientific aspects. The students valued activities that facilitated their curiosity, interest and the management of scientific content and professional working strategies. These findings clearly demonstrate the intended direction of the development of university teaching that should be further encouraged.

Lecturers and coordinators of STSA courses should be aware of the strengths and weaknesses of the pedagogical methods they apply. For university lecturers, international summer courses offer a good opportunity to experiment with a multicultural setting and apply their experiences to the internationalization of university teaching more generally. Students should realize that although collaborating in multicultural groups with open-ended problems is demanding, it also provides rewarding and unique learning experiences. Because students with different cultural backgrounds might have somewhat different expectations about the study methods it would be a good practice to explicitly explain the pedagogical approach to the students during the course (Lauridsen \& Cozart, 2015).

One important conclusion is that structured pedagogical support, guidance and teacher presence are central factors in student-centred methods and, especially, in challenging group assignments. Mascolo (2009) illustrated this using the two-dimensional interplay between individual-social and non-directed-directed modes of teaching and learning. Individual students and student groups need tailored and multifaceted guidance throughout the execution of their tasks. Activating tasks and group assignments to make them even meaningful and motivating as such, are not experienced to be effective or rewarding by the students if they are left alone to complete them, as was often the case in the first type of investigated courses (Self-directed academic studying). Students who are ready to travel abroad and participate in international summer courses are probably more self-regulated and independent than university students on average, but they still appreciate and benefit from carefully designed, well-organized pedagogical activities and good guidance.

The method of investigating each course through one session observation, short lecturer interview and course materials turned out to be a revealing and reasonably inexpensive way to evaluate the pedagogical quality of a large amount of courses; it could be applied in pedagogical research also in other contexts. Regarding the examination of student satisfaction, the students' comments in the open questions demonstrated that the feedback statements did not take into account some essential factors affecting their course experience, such as support from lecturers, authentic expert contents and practices, or international community and social interaction. Research-informed statements could better reveal some central differences in the quality of courses. Based on our study, were recommend, e.g., the following new statements to be used in the feedback form for students: (1) The workload of the course was appropriate; (2) Course assignments supported students' interaction and collaboration; (3) Students' multicultural and multidisciplinary background was taken into account well, and 4) Digital technology was utilized in a meaningful way.

Although the coordinators and lecturers of the Helsinki Summer School courses have freedom to run the courses in their own way, the organizers of the summer school program should provide common pedagogical visions and standards for the overall course offering and support for the instructors, e.g., in the form of training, guidelines and practical recommendations. Common criteria could be defined, for instance, about the proper workload for students, the relative amount of lecturing, the proper amount of contact sessions, the use of digital technology, the promotion of community building by engaging group assignments, the time that should be allocated to social activities and free time, or appropriate assessment methods. Innovative pedagogical approaches could be recommended, introducing good examples and best practices from previous courses. 
To conclude, a successful academic international summer course introduces topical academic and professional knowledge; supports the development of expertise through collaborative, authentic knowledge creation assignments; use methods that strengthen community building and interactive atmosphere; provide students with relevant digital tools for knowledge work, and be run by lecturers who are experts in their field, pedagogically knowledgeable and devoted to sharing their expertise and guidance with students. Similar quality criteria apply to any higher education course. In addition, the multicultural and multidisciplinary assembly of the participants should be explicitly taken into account in the assignments and practices of STSA courses, not only to offer intercultural experiences, but to support multifaceted knowledge sharing and the development of cultural expertise in the field in question. After all, this internationality is the characteristic that makes a difference in the study experience in STSA courses compared to courses in the students' home universities with their local peers.

Even though basic student-centred constructivist pedagogy may provide satisfactory study experiences from the student perspective, as the results of the present research show, we hope that the implementers of international summer courses are also willing to try more novel, innovative pedagogical approaches. In STSA courses, there often are more degrees of freedom than in degree courses regarding the curricula requirements, and a unique, multidisciplinary and intercultural assembly of students and expert lecturers.

Acknowledgements: The study was ordered and funded by the Helsinki Summer School, University of Helsinki. We are especially grateful to the Head of Service Development, Susanna Wolkoff, for her support and keen interest to develop a more systematic approach to summer school teaching. The writing of the article was partially supported by the Argumentative Online Inquiry in Building Students' Knowledge Work Competences (ARONI) research project funded by the Academy of Finland, under Grant 285806.

\section{References}

Anderson, P. H., Lawton, L., Rexeisen, R. J., \& Hubbard, A. C. (2006). Short-term study abroad and intercultural sensitivity: A pilot study. International Journal of Intercultural Relations, 30, 457-469. http://doi.org/10.1016/j.ijintrel.2005.10.004

Atkinson, D., Allert, B., Hirleman, E. D., \& Groll, E. (2006, July 23-28). International short courses and domestic orientation sessions for engineering students. Paper presented at the $9^{\text {th }}$ International Conference on Engineering Education, Puerto Rico. Retrieved from http://www.icee.usm.edu/icee/conferences/icee2006/papers/3565.pdf

Biggs, J. (1996). Enhancing teaching through constructive alignment. Higher Education, 32, 347-364. http://doi.org/10.1007/BF00138871

Biggs, J., \& Tang, C. (2011). Teaching for quality learning at university (4th ed.). Maidenhead, UK: Open University Press/McGraw Hill.

Braun, V., \& Clarke, V. (2006). Using thematic analysis in psychology. Qualitative Research in Psychology, 3, 77-101. http://doi.org/10.1191/1478088706qp063oa

Chieffo, L., \& Griffiths, L. (2004). Large-scale assessment of student attitudes after a short-term study abroad program. Frontiers: The Interdisciplinary Journal of Study Abroad, 10, 165-177. Retrieved from https://frontiersjournal.org/past-volumes/vol-x/

Deloach, S., Saliba, L., Smith, V., \& Tiemann, T. (2003). Developing a global mindset through short-term study abroad. Journal of Teaching in International Business, 15, 37-59. http://doi.org/10.1300/J066v15n01_04

Donnelly-Smith, L. (2009). Global learning through short-term study abroad. Peer Review, 11(4), 12-15. Retrieved from https://search.proquest.com/docview/216603083?accountid=11365

Dwyer, M. M. (2004). More is better: the impact of study abroad program duration. Frontiers: The Interdisciplinary Journal of Study Abroad, 10, 151-164. Retrieved from https://frontiersjournal.org/past-volumes/vol-x/ 
Evaluating the pedagogical quality of international summer courses in a university program

Guest, G. (2013). Describing mixed methods research: an alternative to typologies. Journal of Mixed Methods Research, 7, 141-151. http://doi.org/10.1177/1558689812461179

Hakkarainen, K., Palonen, T., Paavola, S., \& Lehtinen, E. (2004). Communities of Networked Expertise: Professional and Educational Perspectives. Amsterdam: Elsevier.

Herrington, J., \& Oliver, R. (2000). An instructional design framework for authentic learning environments. Educational Technology Research and Development, 48(3), 23-48. http://doi.org/10.1007/BF02319856

Johnson, R. B., \& Onwuegbuzie, A. (2004). Mixed methods research: a research paradigm whose time has come. Educational Researcher, 33(7), 14-26. http://doi.org/10.3102/0013189X033007014

Kember, D., Ho, A., \& Hong, C. (2008). The importance of establishing relevance in motivating student learning. Active Learning in Higher Education, 9, 249-263. http://doi.org/10.1177/1469787408095849

Lakkala, M., Toom, A., Ilomäki, L., \& Muukkonen, H. (2015). Re-designing university courses to support collaborative knowledge creation practices. Australasian Journal of Educational Technology, 31, 521-536. http://doi.org/10.14742/ajet.2526

Lauridsen, K. M., \& Cozart, S. M. (2015). Teaching and learning in the international classroom: quality principles and lessons learned from the IntlUni project. Internationalisation of Higher Education Handbook, 3, 74-89. Retrieved from http://www.eaie.org/eaie-resources/library/publication/Internationalisation-handbook/teaching-learninginternational-classroom.html

Lewis, T. L., \& Niesenbaum, R. A. (2005). Extending the stay: using community-based research and service learning to enhance short-term study abroad. Journal of Studies in International Education, 9, 251-264. http://doi.org/10.1177/1028315305277682

Lizzio, A., Wilson, K., \& Simons, R. (2002). University students' perceptions of the learning environment and academic outcomes: implications for theory and practice. Studies in Higher Education, 27, 27-52. http://doi.org/10.1080/03075070120099359

Mascolo, M. F. (2009). Beyond student-centered and teacher-centered pedagogy: teaching and learning as guided participation. Pedagogy and the Human Sciences, 1, 3-27. Retrieved from http://scholarworks.merrimack.edu/phs/vol1/iss1/6

McCune, V. (2009). Final year biosciences students' willingness to engage: teaching-learning environments, authentic learning experiences and identities. Studies in Higher Education, 34, 347-361. http://doi.org/10.1080/03075070802597127

Mieg, H. A. (2001). The social psychology of expertise: case studies in research, professional domains, and expert roles. Mahwah, NJ: Erlbaum.

Paavola, S., \& Hakkarainen, K. (2014). Trialogical approach for knowledge creation. In S. C. Tan, H. J. So \& J. Yeo (Eds.), Knowledge creation in education (pp. 53-73). Singapore: Springer. https://doi.org/10.1007/978-981-287-047-6_4

Postareff, L., \& Lindblom-Ylänne, S. (2008). Variation in teachers' descriptions of teaching: broadening the understanding of teaching in higher education. Learning and Instruction, 18, 109-120. http://doi.org/10.1016/j.learninstruc.2007.01.008

Prosser, M., \& Trigwell, K. (1999). Understanding learning and teaching. The experience in higher education. Suffolk, UK: Society for Research into Higher Education \& Open University Press.

Sfard, A. (1998). On two metaphors for learning and the dangers of choosing just one. Educational Researcher, 27(2), 4-13. http://doi.org/10.3102/0013189X027002004

Smyth, L., Davila, F., Sloan, T., Rykers, E., Backwell, S., \& Jones, S. B. (2016). How science really works: the student experience of research-led education. Higher Education, 72, 191-207. http://doi.org/10.1007/s10734-015-9945-Z

Stanitski, D., \& Fuellhart, K. (2003). Tools for developing short-term study abroad classes for Geography studies. Journal of Geography, 102, 202-215. http://doi.org/10.1080/00221340308978548

Stein, S. J., Isaacs, G., \& Andrews, T. (2004). Incorporating authentic learning experiences within a university course. Studies in Higher Education, 29, 239-258. http://doi.org/10.1080/0307507042000190813

Tashakkori, A., \& Teddlie, C. (Eds.) (2013). Handbook of mixed methods in social and behavioral research. 
Lakkala, M., Ilomäki, L., Mikkonen, P., Muukkonen, H., \& Toom, A.

Thousand Oaks, CA: Sage Publications.

Timmermans, S., \& Tavory, I. (2012). Theory construction in qualitative research: from grounded theory to abductive analysis. Sociological Theory, 30, 167-186. http://doi.org/10.1177/0735275112457914

Torenbeek, J., \& Meurs, I. (2012). International summer school. EAIE Professional Development Series for International Educators (No. 5). Amsterdam: European Association for International Education. 